\title{
Prenatal developmental toxicity evaluation of IDM01, a botanical composition of 4-hydroxyisoleucine and trigonelline based standardized fenugreek seed extract, during organogenesis period of pregnancy in rats
}

\author{
Pallavi Deshpande ${ }^{1}$, Vishwaraman Mohan ${ }^{1}$, K R Raghunatha Reddy ${ }^{2}$, V R L N Manjunath ${ }^{2}$, Prasad Thakurdesai ${ }^{1, *}$ \\ ${ }^{1}$ Indus Biotech Private Limited, Kondhwa, Pune, Maharashtra, 411048, India. \\ ${ }^{2}$ Bioneeds India Private Limited, Bangalore, Karnataka, 562111, India.
}

\begin{tabular}{l} 
ARTICLE INFO \\
\hline Article history: \\
Received on: 02/06/2017 \\
Accepted on: 16/08/2017 \\
Available online: 30/10/2017 \\
\hline Key words: \\
Developmental toxicity; \\
Fenugreek seeds extract; 4 - \\
hydroxyisoleucine; \\
trigonelline; OECD.
\end{tabular}

\begin{abstract}
The present study was undertaken to assess the developmental toxicity of botanical composition of standardized fenugreek seed extract with markers 4-hydroxyisoleucine and trigonelline (IDM01) during organogenesis period of pregnancy in rats in accordance with OECD guideline (No. 414). Pregnant rats were administered by gavage at 125,250 , and $500 \mathrm{mg} / \mathrm{kg}$ per day of IDM01 over the exposure period of gestational days 5-19 (GD5-GD19). The vehicle control (VC) group was also maintained. The cesarean sections of dams on GD20 were done. All fetuses were examined for external, visceral, and skeletal alterations. IDM01 treatment did not adversely affect maternal parameters (body weights, uterine weight, uterine observations, feed consumption, and gross pathology), and fetal developmental parameters (fetal body weight, crown-rump length, sex ratio and incidence of anomalies) as compared to VC group. In conclusion, the prenatal oral exposure of IDM01 during organogenesis period to pregnant female rats is without any of maternal or developmental (fetotoxicity or teratogenicity) with "No Observed Adverse Effect Level" (NOAEL) greater than $500 \mathrm{mg} / \mathrm{kg} /$ day.
\end{abstract}

\section{INTRODUCTION}

The prevalence of diabetes mellitus (DM) has affected $6.4 \%$ of adults worldwide in 2010 (Danaei et al., 2011, Shaw et al., 2010) which include type 1 and type 2 DM (Alberti and Zimmet, 1998). The chronic hyperglycemia and impaired insulin action/secretion are cardinal features of DM. Type 2 DM accounts for $>90 \%$ of DM and is associated with a metabolic disorder of lipid and carbohydrate (Parillo and Riccardi, 2004). The usefulness of present antidiabetic agents is limited by their side effects. Therefore, search for effective and safe agents

\footnotetext{
* Corresponding Author

Dr. Prasad Thakurdesai, Department of Scientific affairs, Indus Biotech Private Limited, 1, Rahul Residency, Off Salunke Vihar Road, Kondhwa, Pune-411 048, India.Tel: +912064785063, Fax: +912026850039,

E-mail: prasad@indusbiotech.com
}

for control of DM is always going on. According to the World Health Organization (WHO), about 4 billion people (or $80 \%$ of the global population) are using plant based natural remedies for primary health care (Qurishi et al., 2010) because of less frequent side effects than conventional drugs (George, 2011). Furthermore, the presence of unknown and diversified phytoconstituents in natural products have a risk of unknown toxicity that can harm to human health (Palmer et al., 2003, Pittler and Ernst, 2003). On this background, safety assessment of natural products based medicines using their standardized form (extract or fractions) became important for their safe use. One such natural source of medicine that is used as the anti-diabetic medication is fenugreek (Trigonella foenum-graecum L., Fabaceae) seeds. Fenugreek seeds and derived ingredients have a generally regarded as safe (GRAS) status in the United States. The medicinal use of fenugreek seeds are documented in traditional systems of many continents including Asia, and northern Africa for the management of many chronic conditions of 
DM (World Health Organization, 2007). It contains pharmacologically active phytoconstituents such as 4-hydroxyisoleucine (4HI) (Kalshetti et al., 2015), trigonelline (Shah et al., 2006) and galactomannans. Hydro-alcoholic fenugreek seed extract is reported to be efficacious in diabetic rats (Kulkarni et al., 2012).

In the past, the antihyperglycemic activity of IDM01, a $4 \mathrm{HI}^{-}$and trigonelline-based composition of standardized fenugreek seed extract, was reported in animal models of DM (Shah et al., 2006, Shitole et al., 2009), high-fat-diet-induced insulin resistance in mice (Kandhare et al., 2015b) and nonalcoholic steatohepatitis in mice (Kandhare et al., 2015a). Recently, IDM01 was found to be safe in laboratory rats on acute and sub-chronic (90-days repeated dose) administration with noobserved adverse effect level (NOAEL) of $500 \mathrm{mg} / \mathrm{kg}$ without mutagenicity or genotoxicity potential (Deshpande et al., 2017). However, the reproductive safety profile of IDM01 supplementation in females, especially during prenatal exposure with well-accepted international guidelines is not yet reported.

Considering health-promoting potential of IDM01 as a dietary supplement, the present study was undertaken. The present study was aimed at evaluation of the prenatal reproductive safety of oral exposure of IDM01 on pregnant female rats and fetuses during the gestational period. The well accepted international guidelines for such study set forth by Organization for Economic Co-operation and Development (OECD) guideline, OECD. Test number 414 (OECD, 2001)was followed.

\section{MATERIALS AND METHODS}

\section{Animals}

The present study followed the principles of Good Laboratory Practice and animal ethics guidelines in India as per the Committee for the Purpose of Control and Supervision of Experiments on Animals (CPCSEA) for laboratory animal facility' and as per approved protocol (BIO-IAEC 1530) with Institutional Animal Ethics Committee (IAEC) of Bioneeds India Pvt Ltd, Bangalore, India

Male and nulliparous female rats (200-300 g, SpragueDawley strain) aged 10-12 weeks bred in-house were used after acclimatization of 5 days to experimental room conditions before cohabitation. Total 128 female rats and 64 male rats were used. The following housing conditions were maintained: temperature of 19.1-22.9 ${ }^{\circ} \mathrm{C}$, relative humidity of $50 \%$ to $68 \%, 12 \mathrm{~h}: 12 \mathrm{~h}$ fluorescent light dark cycle, $12-15$ air changes per $\mathrm{h})$. The ratio of $1: 2$ (one male to two females) was used for mating in the study. Each morning, the presence of sperm or a vaginal plug of female rats were examined. The day when a vaginal plug or sperm was found was defined as Gestational Day 0 (GD0). The mated females were housed individually in polypropylene cages with stainless steel wire lids. They were allowed to drink purified tap water (purified with UV rays exposure using Aquaguard ${ }^{\circledR}$ (Eureka Forbes Ltd, Mumbai, India) water filter cum purifier system) and fed on Nutrilab ${ }^{\circledR}$ rodent feed (Cargill Provimi India Pvt. Ltd,
Bangalore, India) ad libitum. After mating is confirmed (GD0), pregnant rats were randomly assigned to the vehicle control (VC) and treatment groups.

\section{The test substance}

The test compound, IDM01 was provided by Indus Biotech Private Limited, Pune, India. IDM01 was quantified by reported HPLC methods for assay of marker 4HI (Kulkarni et al., 2012) and trigonelline (Morani et al., 2012). The HPLC quantification assay is performed with following: HPLC model JASCO LC-2000 with UV-2075, Reverse phase C-18 with L1 column, $5 \mu \mathrm{m}$ particle size; Ultraviolet (UV)/visible detector:, 20 $\mu \mathrm{L}$ injection volume, $30 \mathrm{~min}$ run time:; $1.5 \mathrm{~mL} / \mathrm{min}$ flow rate, $\mathrm{UV}$ Detector measured at $347 \mathrm{~nm}$. The $4 \mathrm{HI}$ detection was made with mobile phase: Part A (trifluoroacetic acid, $0.05 \mathrm{~mL}+100 \mathrm{~mL}$ of water) + Part B (40 mL of acetonitrile) in a ratio of 60:40. The trigonelline detection was made with mobile phase: trifluoroacetic acid + water: acetonitrile mixture (60:40). IDM01 sample used for the study had total amino acids with $4 \mathrm{HI}(28.77 \%)$ and trigonelline $(34.8 \%)$.

The fresh solution of IDM01 in was prepared daily in distilled water (as a vehicle) and used in the volume of $10 \mathrm{~mL} / \mathrm{kg}$ to rats for study. The actual dose volume for each animal was calculated based on the most recent body weights recorded on GD5 to GD19.

\section{The study design}

The study was conducted as per guidelines of OECD Test No. 414 (Prenatal Development Toxicity Study) (OECD, 2001). The principles of Good Laboratory Practice [C (97)186/Final] and Standard Operating Procedures at Bioneeds India Private Limited, Bangalore, India were followed.

\section{Prenatal developmental toxicity - Dose-range finding study}

Based on past published data of the no-observed-adverseeffect-level (NOAEL) of IDM01 (Deshpande et al., 2017), the dose levels of $500 \mathrm{mg} / \mathrm{kg}$ was selected as highest dose for the present study. As per OECD guidelines, the two- to four-fold intervals of doses are optimal (OECD, 2001). Therefore, the doses of $125 \mathrm{mg} / \mathrm{kg}$, (one-quarter of $500 \mathrm{mg} / \mathrm{kg}$ ), $250 \mathrm{mg} / \mathrm{kg}$ (one-half of $500 \mathrm{mg} / \mathrm{kg}$ ) and $500 \mathrm{mg} / \mathrm{kg}$ were selected for a main study.

\section{Prenatal developmental toxicity - Main study}

On GD0, 100 female rats ('0' day pregnant) were selected and randomized into 4 groups of 25 rats each. The rats were dosed from GD5 to GD19 either with vehicle (G1: VC) or IDM01 (G2:125 mg/kg, G3: $250 \mathrm{mg} / \mathrm{kg}$ or G4: $500 \mathrm{mg} / \mathrm{kg}$ ), encompassing the entire period of gestation from uterine implantation to organogenesis and fetal growth. Dose levels were selected based on no observed adverse effect level (NOAEL) of IDM01 in 90 days repeated dose toxicity study $(500 \mathrm{mg} / \mathrm{kg}$ body weight). Data on clinical signs of females was collected daily throughout gestation. Body weights and food consumption of each 
dam were recorded on GD0, GD5, GD8, GD11, GD14, GD17 and just prior to their sacrifice on GD20. All rats were euthanized on GD20 by $\mathrm{CO} 2$ asphyxiation. The abdominal incision is made, and the number of corpora lutea in ovaries of each dam were examined. The uterine horns were removed, and the following parameters were recorded: the position of fetus, number of fetuses (total, live and dead), number of resorptions, the position of resorptions, the gender and the body weight of each fetus. The preimplantation and post-implantation loss were calculated as follows: pre-implantations loss $=[$ (no. corpora lutea - no. implantations)/ no. corpora lutea $\times 100$ and post-implantation loss $=[$ (no. implantations - no. live fetuses $) /$ no. implantations $] \times 100$ (Burdan et al., 2005). The uteri of rats that appeared non-pregnant were stained with $10 \%$ aqueous ammonium sulfide solution and examined for evidence of early resorptions (Taylor, 1986a). All live fetuses were examined for external abnormalities. One-half of the fetuses from each litter were eviscerated, skinned and fixed in 95\% ethanol. They were double stained for skeletal examination using Alizarin red S (bones) and Alcian blue (cartilage). The fetal specimens were examined under a stereomicroscope for the presence or absence of skeletal malformation or variations. Remaining half fetuses were subjected to soft tissue examination using microdissection technique for body and a free-hand serial sectioning technique for head (Wilson technique) (Monie et al.). After examination, the fetuses along with organs were preserved in a solution of glycerin. The visceral abnormalities and variations were observed and recorded (Taylor, 1986b).

\section{Statistical analysis}

The data was presented as the mean \pm standard deviation (SD).The one-way analysis of variance (ANOVA), and Dunnett's test was used to analyze following parameters: Gestational body weights and changes and daily food consumption, gravid uterus and female). The Kruskal-Wallis test (non-parametric equivalent of ANOVA), followed by the Mann-Whitney test was applied to parameters of numbers of corpora lutea, implantations per female, number of resorptions, litter size, number of fetuses (total, live and dead), sex ratio (male/female), incidences of malformations (fetal visceral and skeletal). Numbers of pregnant and non-pregnant female rats, dead and live fetuses per dam were analyzed by using Chi-square test. IDM01 treated groups were compared with respective VC group. The values were considered significant at $\mathrm{P}$ $<0.05$.

\section{RESULTS}

\section{Maternal toxicity}

No evidence of abnormal clinical signs was observed in any dam during the study. No statistically significant difference in body weight gain of pregnant rats between IDM01 treated groups and VC group was found. No statistically significant difference was found between the treatment groups and controls group for maternal weight gain, food intake, or hematology and biochemical parameters (Table 1). No treatment-related changes in average feed consumption (g/dam/day and $\mathrm{g} / \mathrm{kg}$ body weight/day) were noted in IDM01 treated groups and VC during the gestation period. No treatment-related gross pathological findings were reported in IDM01 treated groups and VC group animals.

\section{Embryo-fetal examinations}

The gravid uterine weights, number of corpora lutea, the number of fetuses, the number of early and late resorptions, the percentage of pre-and post-implantation loss, crown-rump length $(\mathrm{mm})$, male/female sex ratio and fetal body weight $(\mathrm{g})$ were not significant in groups G2, G3 and G4 as compared to G1 (VC) (Table 2).

Table 1: Effects of IDM01 on maternal parameters during organogenesis period.

\begin{tabular}{lcccc}
\hline \multirow{2}{*}{\multicolumn{1}{c}{ Parameters }} & \multicolumn{4}{c}{ IDM01 (mg/kg) } \\
\cline { 2 - 5 } & VC & $\mathbf{1 2 5}$ & $\mathbf{2 5 0}$ & $\mathbf{5 0 0}$ \\
\cline { 2 - 5 } & G1 & G2 & G3 & G4 \\
\hline Pregnancy data & 25 & & & 25 \\
Initial Animals per Group & 21 & 21 & 24 & 24 \\
Confirmed Pregnancy at Necropsy & 84 & 84 & 96 & 96 \\
Pregnancy Rate (\%) & & & \\
Maternal data & $251.71 \pm 20.53$ & $248.21 \pm 15.91$ & $254.92 \pm 20.16$ & $255.81 \pm 17.61$ \\
Body Weight (g)/GD 5 & $355.99 \pm 30.87$ & $345.93 \pm 25.70$ & $356.7 \pm 34.54$ & $350.32 \pm 30.07$ \\
Final Body Weight (g)/GD 20 & $104.28 \pm 17.22$ & $97.72 \pm 15.86$ & $101.77 \pm 18.64$ & $94.51 \pm 17.37$ \\
Body Weight Change (g) during GD 5 to 20 & $36.56 \pm 11.07$ & $31.50 \pm 11.46$ & $30.95 \pm 11.44$ & $31.85 \pm 10.42$ \\
Corrected Body Weight (g) & $25.07 \pm 3.20$ & $24.07 \pm 2.90$ & $24.18 \pm 3.38$ & $24.1 \pm 2.87$ \\
Feed Consumption (g/dam/day) GD 5 to 20 & $83.86 \pm 7.78$ & $81.97 \pm 8.29$ & $79.98 \pm 6.72$ & $80.4 \pm 6.36$ \\
Feed Consumption (g/kg body weight/day) GD 5 to 20 & &
\end{tabular}

Values are expressed as Mean \pm SD. $n=25$ female rats per group were randomized. VC- Vehicle control, GD- Gestational Day. 
Table 2: Effects of IDM01 on reproductive parameters during organogenesis period.

\begin{tabular}{|c|c|c|c|c|}
\hline \multirow{3}{*}{ Parameters } & \multicolumn{4}{|c|}{ IDM01 (mg/kg) } \\
\hline & $\mathrm{VC}$ & 125 & 250 & 500 \\
\hline & G1 & G2 & G3 & G4 \\
\hline \multicolumn{5}{|l|}{ Uterine observations } \\
\hline All litters ${ }^{\mathrm{a}}$ & 21 & 21 & 24 & 24 \\
\hline Gravid uterus weight (g) & $67.72 \pm 13.77$ & $66.21 \pm 13.08$ & $70.82 \pm 13.27$ & $62.66 \pm 15.93$ \\
\hline Corpora Lutea (no.) & $11.8 \pm 2.3$ & $11.6 \pm 2.2$ & $12.4 \pm 2.2$ & $11.2 \pm 2.5$ \\
\hline Implantation per dam (no.) & $11.8 \pm 2.3$ & $11.6 \pm 2.2$ & $12.4 \pm 2.2$ & $11.1 \pm 2.5$ \\
\hline Male/female sex ratio (no.) & $1.2 \pm 0.9$ & $1.2 \pm 0.7$ & $1.2 \pm 0.9$ & $2.1 \pm 2.6$ \\
\hline Litter size (no.) & $11.7 \pm 2.4$ & $11.5 \pm 2.2$ & $12.2 \pm 2.2$ & $10.9 \pm 2.7$ \\
\hline Live fetuses per dam (no.) & $11.7 \pm 2.4$ & $11.5 \pm 2.2$ & $12.2 \pm 2.2$ & $10.9 \pm 2.7$ \\
\hline Dead fetuses per dam (no.) & $0 \pm 0$ & $0 \pm 0$ & $0 \pm 0$ & $0 \pm 0$ \\
\hline Early resorptions per dam (no.) & $0.05 \pm 0.2$ & $0.1 \pm 0.3$ & $0.13 \pm 0.3$ & $0.21 \pm 0.5$ \\
\hline Late resorptions per dam (no.) & $0 \pm 0$ & $0 \pm 0$ & $0.04 \pm 0.2$ & $0 \pm 0$ \\
\hline Pre-implantation loss $(\%)^{\mathrm{b}}$ & $0 \pm 0$ & $0 \pm 0$ & $0 \pm 0$ & $0.3 \pm 1.6$ \\
\hline Post-implantation loss $(\%)^{\mathrm{c}}$ & $0.5 \pm 2.2$ & $1 \pm 3.2$ & $1.4 \pm 3.2$ & $2.7 \pm 8.4$ \\
\hline \multicolumn{5}{|l|}{ Litter data } \\
\hline Live male fetuses (no.) & $5.8 \pm 2.1$ & $5.7 \pm 2.2$ & $6 \pm 2.2$ & $5.8 \pm 2.2$ \\
\hline Live female fetuses (no.) & $5.9 \pm 2.2$ & $5.9 \pm 2.2$ & $6.3 \pm 2.5$ & $5.1 \pm 2.6$ \\
\hline Fetal weight per dam (g) & $3.65 \pm 0.19$ & $3.6 \pm 0.25$ & $3.72 \pm 0.33$ & $3.63 \pm 0.41$ \\
\hline Male fetal weight per dam (g) & $3.77 \pm 0.20$ & $3.71 \pm 0.25$ & $3.84 \pm 0.30$ & $3.68 \pm 0.47$ \\
\hline Female fetal weight per dam (g) & $3.56 \pm 0.25$ & $3.48 \pm 0.24$ & $3.59 \pm 0.37$ & $3.56 \pm 0.43$ \\
\hline Fetal crown rump length per dam (mm) & $35.81 \pm 1.17$ & $35.85 \pm 1.16$ & $36.20 \pm 0.92$ & $36.26 \pm 1.24$ \\
\hline Male fetal crown rump length per dam (mm) & $36.03 \pm 1.24$ & $36.1 \pm 1.23$ & $36.5 \pm 0.91$ & $36.34 \pm 1.42$ \\
\hline Female fetal crown rump length per dam (mm) & $35.64 \pm 1.17$ & $35.58 \pm 1.20$ & $35.81 \pm 1.18$ & $36.02 \pm 1.31$ \\
\hline
\end{tabular}

Table 3: Effects of IDM01 on fetal malformations and variations during organogenesis period.

\begin{tabular}{|c|c|c|c|c|}
\hline \multirow{3}{*}{ Parameters } & \multicolumn{4}{|c|}{ IDM01 (mg/kg) } \\
\hline & VC & 125 & 250 & 500 \\
\hline & G1 & G2 & G3 & G4 \\
\hline \multicolumn{5}{|l|}{ Total No. Fetuses (litters) examined } \\
\hline External & $246(21)$ & $242(21)$ & $293(24)$ & $262(24)$ \\
\hline Visceral & $118(21)$ & $116(21)$ & $142(24)$ & $127(24)$ \\
\hline Skeletal & $128(21)$ & $126(21)$ & $151(24)$ & $135(24)$ \\
\hline External Malformations & $0(0)$ & $0(0)$ & $0(0)$ & $0(0)$ \\
\hline External Variations & $0(0)$ & $0(0)$ & $0(0)$ & $0(0)$ \\
\hline \multicolumn{5}{|l|}{ Visceral Variations } \\
\hline Right Kidney - Renal pelvis Dilation & $2(2)$ & $1(1)$ & $1(1)$ & $2(2)$ \\
\hline Left Kidney - Renal pelvis Dilation & $0(0)$ & $0(0)$ & $1(1)$ & $0(0)$ \\
\hline \multicolumn{5}{|l|}{ Skeletal Variations } \\
\hline \multicolumn{5}{|l|}{ Sternum Variations } \\
\hline Sternum No. 4 - Poor ossification & $1(1)$ & $0(0)$ & $0(0)$ & $1(1)$ \\
\hline Sternum No. 5 - Poor Ossification & $2(2)$ & $2(2)$ & $8(7)$ & $5(5)$ \\
\hline Sternum No. 6 - Poor Ossification & $4(4)$ & $7(6)$ & $10(10)$ & $12(10)$ \\
\hline Metacarpal No. 5 - Poor Ossification & $0(0)$ & $6(5)$ & $7(7)$ & $9(8)$ \\
\hline \multicolumn{5}{|l|}{ Thoracic Vertebrae Variations } \\
\hline Centrum No. 10 - Asymmetric Bi-lobed & $0(0)$ & $1(1)$ & $2(2)$ & $2(2)$ \\
\hline Centrum No. 11 - Asymmetric Bi-lobed & $0(0)$ & $1(1)$ & $3(2)$ & $3(3)$ \\
\hline Centrum No. 12 - Asymmetric Bi-lobed & $0(0)$ & $1(1)$ & $4(2)$ & $3(3)$ \\
\hline Centrum No. 13 - Asymmetric Bi-lobed & $0(0)$ & $0(0)$ & $2(1)$ & $0(0)$ \\
\hline \multicolumn{5}{|l|}{ Skeletal Malformations } \\
\hline \multicolumn{5}{|l|}{ Thoracic Vertebrae Malformations } \\
\hline Centrum No. 10 - Split & $0(0)$ & $1(1)$ & $0(0)$ & $0(0)$ \\
\hline Centrum No. 11 - Split & $1(1)$ & $2(2)$ & $3(3)$ & $0(0)$ \\
\hline Centrum No. 12 - Split & $1(1)$ & $3(3)$ & $1(1)$ & $1(1)$ \\
\hline Centrum No. 13 - Split & $0(0)$ & $3(1)$ & $0(0)$ & $1(1)$ \\
\hline \multicolumn{5}{|l|}{ Fore Limb Malformations } \\
\hline Proximal phalanx No. 3 and 4 - Absent (Bila & $12(9)$ & $15(11)$ & $24(15)$ & $17(10)$ \\
\hline
\end{tabular}

Fetuses from pregnant female rats per group were examined. The incidence of the individual defect is presented as a number of fetuses (numbers of litters). VCVehicle control.

\section{Fetal malformations and variations}

The data of fetal malformations and variations during organogenesis period showed no significant effects of IDM01 as compared with VC (Table 3). In general, no external abnormalities were noted within any group during the external examination of these fetuses. Following variations of fetuses were noted during visceral examination: 2 of 118 examined fetuses ( 2 of 21 litters examined) from Group G1 (0 mg/kg), 1 of 116 examined fetuses 

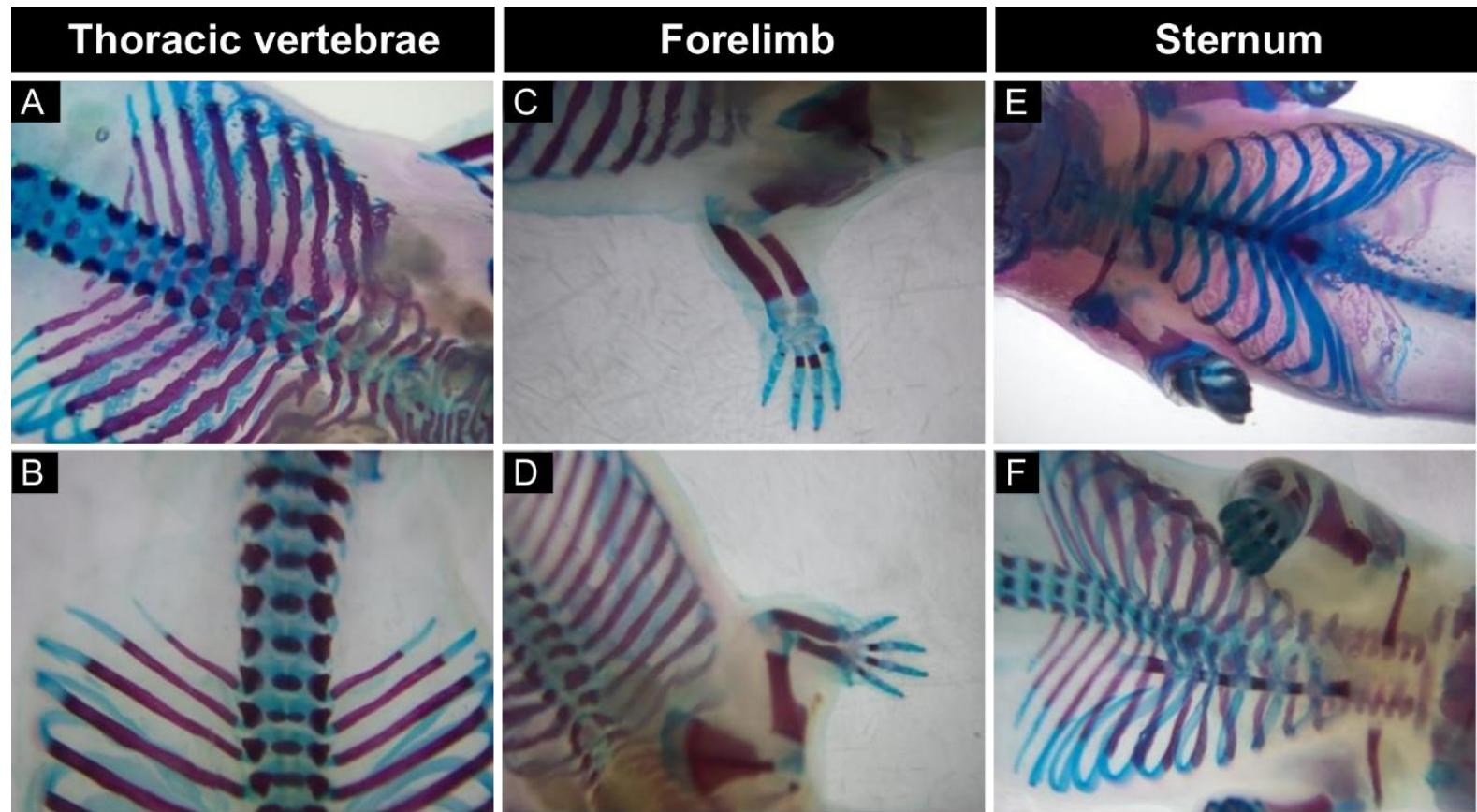

Fig.1. The photos of normal development and variations observed during skeletal examination: (A) Normal thoracic vertebrae (B) thoracic vertebrae with asymmetric bilobed variation (C) Normal forelimb (D) Forelimb with poorly ossified metacarpal (E) Normal sternum (F) Poorly ossified sternum.

(1 of 21 litters examined) from Group G2 (125 mg/kg), 1 of 142 examined fetuses ( 1 of 24 litters examined) from Group G3 (250 $\mathrm{mg} / \mathrm{kg}$ ) and 2 of 127 examined fetuses ( 2 of 24 litters examined) from Group G4 $(500 \mathrm{mg} / \mathrm{kg})$ were noted to have right kidney renal pelvic dilation. 0 of 118 examined fetuses ( 0 of 21 litters examined) from Group G1 (0 mg/kg), 0 of 116 examined fetuses (0 of 21 litters examined) from Group G2 (125 mg/kg), 1 of 142 examined fetuses ( 1 of 24 litters examined) from Group G3 (250 $\mathrm{mg} / \mathrm{kg}$ ) and 0 of 127 examined fetuses (0 of 24 litters examined) from Group G4 $(500 \mathrm{mg} / \mathrm{kg})$ were noted to have left kidney renal pelvic dilation.

The noted anomalies [renal pelvis dilation] are common findings for fetuses of this species and strain. The morphological observations neither seen in a dose-dependent manner nor was the severity of the anomaly increased with dose. This result supports the conclusion that the findings are incidental and that the IDM01did not produce an adverse effect on the development of the soft tissues. The representative photos of the variations and malformations that are observed during the skeletal examination are presented as Fig. 1. During the skeletal examination of fetuses the following malformations were noted: 1 of 128 examined fetuses ( 1 of 21 litters examined) with split thoracic vertebrae centrum No. 11 and 12, 12 of 128 examined fetuses ( 9 of 21 litters examined) with the absence of proximal phalanges No. 3 and 4 of forelimb from Group G1 (0 mg/kg) were noted. 1 of 126 examined fetuses ( 1 of 21 litters examined) with split thoracic vertebrae centrum No. 10, 2 of 126 examined fetuses ( 2 of 21 litters examined) with split thoracic vertebrae centrum No. 11, 3 of 126 examined fetuses ( 3 of 21 litters examined) with split thoracic vertebrae centrum No. 12, 3 of 126 examined fetuses ( 1 of 21 litters examined) with split thoracic vertebrae centrum No. 13, 15 of 126 examined fetuses (11 of 21 litters examined) with absence of proximal phalanges No. 3 and 4 of forelimb from Group G2 (125 mg/kg) were noted. 3 of 151 examined fetuses (3 of 24 litters examined) with split thoracic vertebrae centrum No. 11,1 of 151 examined fetuses ( 1 of 24 litters examined) with split thoracic vertebrae centrum No. 12, 24 of 151 examined fetuses (15 of 24 litters examined) with the absence of proximal phalanges No. 3 and 4 of forelimb from Group G3 $(250 \mathrm{mg} / \mathrm{kg})$ were noted. 1 of 135 examined fetuses ( 1 of 24 litters examined) with split thoracic vertebrae centrum No. 12, 1 of 135 examined fetuses ( 1 of 24 litters examined) with split thoracic vertebrae centrum No. 13, 17 of 135 examined fetuses ( 10 of 24 litters examined) with the absence of proximal phalanges No. 3 and 4 of forelimb from Group G4 $(500 \mathrm{mg} / \mathrm{kg})$ were noted. During skeletal examination of fetuses the following variations were noted: 1 of 128 examined fetuses ( 1 of 21 litters examined) with poorly ossified sternum No. 4, 2 of 128 examined fetuses ( 2 of 21 litters examined) with poorly ossified sternum No. 5 and 4 of 128 examined fetuses (4 of 21 litters examined) with poorly ossified sternum No. 6 from Group G1 $(0 \mathrm{mg} / \mathrm{kg})$ were noted. 2 of 126 examined fetuses ( 2 of 21 litters examined) with poorly ossified sternum No. 5, 7 of 126 examined fetuses ( 6 of 21 litters examined) with poorly ossified sternum No. 6, 6 of 126 examined fetuses (5 of 21 litters examined) with poorly ossified metacarpal No. 5, 1 of 126 examined fetuses ( 1 of 21 litters examined) with asymmetric bilobed thoracic vertebrae centrum No. 10, 11 and 12 from Group G2 $(125 \mathrm{mg} / \mathrm{kg}$ ) were noted. 8 of 151 examined fetuses (7 of 24 
litters examined) with poorly ossified sternum No. 5, 10 of 151 examined fetuses (10 of 24 litters examined) with poorly ossified sternum No. 6, 7 of 151 examined fetuses (7 of 24 litters examined) with poorly ossified metacarpal No. 5, 2 of 151 examined fetuses ( 2 of 24 litters examined) with asymmetric bilobed thoracic vertebrae centrum No. 10, 3 of 151 examined fetuses ( 2 of 24 litters examined) with asymmetric bi-lobed thoracic vertebrae centrum No. 11, 4 of 151 examined fetuses ( 2 of 24 litters examined) with asymmetric bi-lobed thoracic vertebrae centrum No. 12, 2 of 151 examined fetuses (1 of 24 litters examined) with asymmetric bi-lobed thoracic vertebrae centrum No. 13 from Group G3 (250 mg/kg) were noted. 1 of 135 examined fetuses (1 of 24 litters examined) with poorly ossified sternum No. 4, 5 of 135 examined fetuses (5 of 24 litters examined) with poorly ossified sternum No. 5, 12 of 135 examined fetuses (10 of 24 litters examined) with poorly ossified sternum No. 6, 9 of 135 examined fetuses (8 of 24 litters examined) with poorly ossified metacarpal No. 5, 2 of 135 examined fetuses ( 2 of 24 litters examined) with asymmetric bi-lobed thoracic vertebrae centrum No. 10, 3 of 135 examined fetuses (3 of 24 litters examined) with asymmetric bi-lobed thoracic vertebrae centrum No. 11 and 12 from Group G4 (500 mg/kg) were noted. Occasional differences that occurred between groups treated with the IDM01 and VC showed no dose-dependency and were caused by higher as well as lower stages of development and therefore, considered not to be treatment-related.

\section{DISCUSSION}

Many botanical extracts used for the treatment of diseases and health improvement are reported with serious side effects (Navarro et al., 2017, Stieger et al., 2017, Valli and Giardina, 2002). Many pharmaceuticals that are in practice today are isolated chemicals (phytoconstituents) from biologically active plants. Though natural products have become increasingly popular throughout the world, one of the major impediments in its acceptance is the poor standard of quality control profile and methods (Folashade et al., 2012). The quality of the natural product or herbal medicines largely depends on the profile of the constituents in the final product and has implications on the constancy of efficacy and safety. Hence, confirmation of safety profile of natural products that are standardized form is essential for clinical applications (Kunle et al., 2012). Fenugreek seed based extracts showed good clinical potential for diverse clinical applications as supplements. However, published literature regarding the reproductive safety profile of fenugreek extracts showed inconsistently. These differences can be attributed mainly due to differences in standardization methods, marker compounds, use of solvents for extraction, compliance to applicable guidelines and route of administration used in these published studies (Ahirwar et al., 2010; Dande and Patil, 2012; Sharma and Bhinda, 2005; Araee et al., 2009; Aswar et al., 2009; Deshpande et al., 2016; Khalki et al., 2010; Mital and Gopaldas, 1976; Modaresi et al., 2012). For example, oral administration during day 1-10 of pregnancy of ethanol extract of fenugreek $(500 \mathrm{mg} / \mathrm{kg} /$ day $)$ seeds consisting mainly of alkaloids, saponins, and flavonoids, was found to have anti-implantation and estrogenic agent in female rat and mouse respectively (Ahirwar et al., 2010). The previous studies showed declined uterine and ovarian weights in adult female rats by a steroidal extract of fenugreek $(100 \mathrm{mg} /$ day/rat, 15 days treatment) feeding (Sharma and Bhinda, 2005). Abortifacient and anti-implantation properties of saponin extract of fenugreek seeds with $62 \%$ resorption at $200 \mathrm{mg} / \mathrm{kg}$ body weight in female rats are also reported (Dande and Patil, 2012). Moreover, hydroalcoholic extract of fenugreek seed at 50,100 and $200 \mathrm{mg} / \mathrm{kg}$ by intraperitoneal injection for 20 days was also shown to reduce folliculogenesis and destroy ovary tissue in female Balb/C mice (Modaresi et al., 2012). It is also shown that fenugreek seed extract administered orally, produced a significant dose-dependent reduction in the number of fetuses per litter (Khalki et al., 2010).

On the other hand, a study conducted in pregnant rats treated by fenugreek seed at 5 or $20 \%$ of the diet did not observe any effect on fertility, growth, and development of the fetus (Mital and Gopaldas, 1976). In addition, $75 \mathrm{mg} / \mathrm{kg}$ of trigonelline administered orally to pregnant and non-pregnant female rats showed no anti-fertility or abortifacient effects in animals (Aswar et al., 2009). Recently, the oral exposure of low molecular weight galactomannans based standardized fenugreek seed extract (LMWGAL-TF) upto1000 mg/kg body weight of pregnant female rats and their fetuses was found safe (Deshpande et al., 2016).

Therefore, the present study was aimed at reproductive safety profile during prenatal exposure of IDM01 (a botanical composition of $4 \mathrm{HI}$ and trigonelline based standardized fenugreek seed extract) in pregnant female rats and their developing fetuses following OECD test guideline No. 414, "Prenatal Developmental Toxicity Study", adopted on 22 January 2001 (OECD, 2001). The present study results of no adverse effects as evident by maternal and fetal toxicity parameter assessments in pregnant female rats support the safety of IDM01 during exposure in the prenatal period. For the developmental toxicity assessment, the results of the experiment support the conclusion that the NOAEL [No Observed Adverse Effect Level] of IDM01 for the developmental toxicity endpoint was more than $500 \mathrm{mg} / \mathrm{kg}$. The prenatal oral exposure of IDM01 during organogenesis period to pregnant female rats did not show maternal, embryo-fetal toxicity or teratogenicity up to a dose of $500 \mathrm{mg} / \mathrm{kg} /$ day. The results of present study showed no evidence of teratogenic effects after oral administration of IDM01 up to $500 \mathrm{mg} / \mathrm{kg} / \mathrm{day}$. Calculation of Human equivalent dose (HED) from NOAEL dose can be done using USFDA guidance for Industry (Center for Drug Evaluation and Research, 2005). On the basis of NOAEL of IDM01 = 500 $\mathrm{mg} / \mathrm{kg}$, HED can be calculated as $4.86 \mathrm{~g}$ (considering the average human weight of $60 \mathrm{~kg}$ ).

\section{CONCLUSIONS}

The oral prenatal exposure of IDM01 during the organogenesis period in pregnant female rats was found safe with NOAEL of $500 \mathrm{mg} / \mathrm{kg}$. This safety information of prenatal exposure of IDM01 in pregnant female rats forms an important 
basis for the clinical development as a safe dietary supplement or botanical agent for general and female specific applications.

\section{ACKNOWLEDGEMENTS}

The acknowledgement to Bioneeds Private Limited, Bangalore, India for providing infrastructural facilities.

\section{Financial support and sponsorship: Nil.}

Conflict of Interests: There are no conflicts of interest.

\section{REFERENCES}

Ahirwar D, Ahirwar B, Kharya M. Evaluation of antifertility activity of Trigonella foenum graecum seeds. Der Pharmacia Sinica. 2010; 1: 33-9.

Alberti KG, Zimmet PZ. Definition, diagnosis and classification of diabetes mellitus and its complications. Part 1: diagnosis and classification of diabetes mellitus provisional report of a WHO consultation. Diabet Med. 1998; 15:539-53.

Araee M, Norouzi M, Habibi G, Sheikhvatan M. Toxicity of Trigonella foenum graecum (Fenugreek) in bone marrow cell proliferation in rat. Pak J Pharm Sci. 2009; 22:126-30.

Aswar U, Mohan V, Bodhankar S. Effect of trigonelline on fertility in female rats. International Journal of Green Pharmacy. 2009; 3: 220 .

Burdan F, Szumiło J, Dudka J, Klepacz R, Błaszczak M, Solecki M, et al. Morphological studies in modern teratological investigations. Folia Morphol (Praha). 2005; 64:1-8.

Center for Drug Evaluation and Research. Guidance for Industry: Estimating the maximum safe starting dose in initial clinical trials for therapeutics in adult healthy volunteers. In: US Department of Health and Human Services, editor. Rockville, MD, USA: US Food and Drug Administration; 2005.

Danaei G, Finucane MM, Lu Y, Singh GM, Cowan MJ, Paciorek CJ, et al. National, regional, and global trends in fasting plasma glucose and diabetes prevalence since 1980: systematic analysis of health examination surveys and epidemiological studies with 370 country-years and 2.7 million participants. Lancet. 2011; 378:31-40.

Dande P, Patil S. Evaluation of Saponins from Trigonella foenum graecum Seeds for its Antifertility Activity. Asian J Pharm Clin Res. 2012; 5:154-7.

Deshpande P, Mohan V, Thakurdesai P. Preclinical safety assessment of glycosides based standardized fenugreek seeds extract. J Appl Pharm Sci. 2016; 6:179-88.

Deshpande P, Mohan V, Thakurdesai P. Preclinical toxicological evaluation of IDM01: The botanical composition of 4Hydroxyisoleucine- and trigonelline-based standardized fenugreek seed extract. Pharmacogn Res. 2017; 9:138-50.

Folashade O, Omoregie H, Ochogu P. Standardization of herbal medicines-A review. Int J Biodivers Conserv. 2012; 4:101-12.

George P. Concerns regarding the safety and toxicity of medicinal plants-An overview. J Appl Pharm Sci. 2011; 1:40-4.

Kalshetti P, Alluri R, Thakurdesai PA. Effects of 4 hydroxyisoleucine from Fenugreek Seeds on Depression - like Behavior in Socially Isolated Olfactory Bulbectomized Rats. Pharmacogn Mag. 2015; 11:S388-S96.

Kandhare A, Bodhankar S, Mohan V, Thakurdesai P. Therapeutic potential of Synergistic composition from fenugreek seeds $\left(\right.$ Sugaheal ${ }^{\circledR}$ ) against nonalcoholic steatohepatitis in C57BL/6 mice. 2nd International Congress of Society for Ethnopharmacology (SFEC - 2015) Nagpur: Society for Ethnopharmacology 2015 a.

Kandhare A, Bodhankar SL, Mohan V, Thakurdesai PA. Prophylactic efficacy and possible mechanisms of oligosaccharides based standardized fenugreek seed extract on high-fat diet-induced insulin resistance in C57BL/6 mice. J Appl Pharm Sci. 2015b; 5:3545 .

Khalki L, M'Hamed S B, Bennis M, Chait A, Sokar Z. Evaluation of the developmental toxicity of the aqueous extract from Trigonella foenum-graecum (L.) in mice. J Ethnopharmacol. 2010; 131:321-5.

Kulkarni C, Bodhankar SL, Ghule AE, Mohan V, Thakurdesai PA. Antidiabetic activity of Trigonella foenum-graecum L. seeds extract (IND01) in neonatal streptozotocin-induced (n-STZ) rats. Diabetol Croat. 2012; 41:29-40.

Kunle OF, Egharevba HO, Ahmadu PO. Standardization of herbal medicines-A review. Int J Biodivers Conserv. 2012; 4:101-12.

Mital N, Gopaldas T. Effect of fenugreek (trigonella foenum graecum) seed based diets on the lactational performance in albino rats. Nutr Rep Int. 1976; 33:477-84.

Modaresi M, Jalalizand A, Mahdian B. The effect of hydroalcoholic extract of fenugreek seeds on female reproductive hormones in mice. International Conference on Applied Life Sciences (ICALS2012). Turkey: Intech Open Access Publisher; 2012. p. $437-$ 42.

Monie IW, Kho KG, Morgan J. Dissection Procedures for Rat Foetuses Permitting Alizarin Red Staining of Skeleton and Histological Study of Viscera. p. 163-73.

Morani AS, Bodhankar SL, Mohan V, Thakurdesai PA. Ameliorative effects of standardized extract from Trigonella foenumgraecum L. seeds on painful peripheral neuropathy in rats. Asian Pacific Journal of Tropical Medicine. 2012; 5:385-90.

Navarro VJ, Khan I, Björnsson E, Seeff LB, Serrano J, Hoofnagle JH. Liver injury from herbal and dietary supplements. Hepatology. 2017; 65:363-73.

OECD. Test No. 414: Prenatal Development Toxicity Study. OECD Guidelines for the Testing of Chemicals, Section 4: Health Effects. Paris: OECD Publishing; 2001.

Palmer ME, Haller C, McKinney PE, Klein-Schwartz W, Tschirgi A, Smolinske SC, et al. Adverse events associated with dietary supplements: an observational study. Lancet. 2003; 361:101-6.

Parillo M, Riccardi G. Diet composition and the risk of type 2 diabetes: epidemiological and clinical evidence. Br J Nutr. 2004; 92:7-19.

Pittler MH, Ernst E. Systematic review: hepatotoxic events associated with herbal medicinal products. Aliment Pharmacol Ther. 2003; 18:451-71.

Qurishi Y, Hamid A, Zargar M, Singh SK, Saxena AK. Potential role of natural molecules in health and disease: Importance of boswellic acid. J Med Plant Res. 2010; 4:2778-86.

Shah S, Bodhankar S, Badole S, Kamble H, Mohan V. Effect of trigonelline: an active compound from Trigonella foenumgraecum Linn. in alloxan induced diabetes in mice. J Cell Tissue Res. 2006; 6:585.

Sharma J, Bhinda A. Antifertility activity of steroidal extract of Trigonella foenum-graecum (seeds) in female rats. Asian J Exp Sci. 2005; 19:115-20.

Shaw JE, Sicree RA, Zimmet PZ. Global estimates of the prevalence of diabetes for 2010 and 2030. Diabetes Res Clin Pract. 2010; 87:4-14.

Shitole P, Badole S, Bodhankar SL, Mihan V, Bhaskaran S. Anti-hyperglycaemic activity of IND01 and its interaction with glyburide and pioglitazone in alloxan induced diabetic mice. Int $\mathrm{J}$ Diab Metab. 2009; 17:21-6. 
Stieger B, Mahdi ZM, Jäger W. Intestinal and hepatocellular transporters: Therapeutic effects and drug interactions of herbal supplements. Annu Rev Pharmacol Toxicol. 2017; 57:399-416.

Taylor P. Maternal necropsy and foetal examination.

Practical Teratology. 1986a:21-3.

Taylor P. Practical Teratology. London: Academic Press; 1986b.

Valli G, Giardina E-GV. Benefits, adverse effects and drug interactionsof herbal therapies with cardiovascular effects. J Am Coll Cardiol. 2002; 39:1083-95.

World Health Organization. WHO Monographs on Selected Medicinal Plants. Geneva: World Health Organization; 2007.

\section{How to cite this article:}

Deshpande P, Mohan V, Reddy KRR, Manjunath VR, Thakurdesai P. Prenatal developmental toxicity evaluation of IDM01, a botanical composition of 4-hydroxyisoleucine and trigonelline based standardized fenugreek seed extract, during organogenesis period of pregnancy in rats. J App Pharm Sci, 2017; 7 (10): 062069. 